\title{
SINERGIA
}

REVISTA DO INSTITUTO DE CIÊNCIAS ECONÔMICAS, ADMINISTRATIVAS E CONTÁBEIS (ICEAC)

\section{A INFLUÊNCIA DO SISTEMA DE INFORMAÇÃO CONTÁBIL COMO INSTRUMENTO DE APOIO À GERAÇÃO DE INFORMAÇÕES FIDEDIGNAS PELA CONTROLADORIA: UM ESTUDO DE CASO}

\author{
CRISTIANO MOREIRA SILVA \\ JOSÉ RONALDO DA SILVA* \\ VICTOR HUGO PEREIRA \\ DAVSON MANSUR IRFFI SILVA
}

\begin{abstract}
RESUMO
Com o surgimento dos Sistemas de Informações Contábeis (SIC), a contabilização em papéis perdeu espaço, e o contador deixou de ser apenas guardador de livros, transformando-se em peça fundamental na tomada de decisão. Com uma economia totalmente globalizada, as decisões precisam ser tomadas instantaneamente para garantir o bom desenvolvimento das atividades comerciais, otimizando o resultado econômico. Os SICs tornaram-se um meio de alcançar esse objetivo por meio do eficiente controle das informações gerenciais. O presente objetivou identificar a influência do SIC como instrumento de apoio à geração de informações fidedignas pela Controladoria. Trata-se de um estudo qualitativo cuja metodologia aplicada foi a pesquisa bibliográfica e documental, por meio também de um estudo de caso em uma empresa de construção civil, buscando captar a percepção dos colaboradores acerca da utilização do SIC como ferramenta de suporte e seu papel no processamento da informação contábil na organização. Concluiu-se que o SIC possui aspectos que o diferenciam dos demais sistemas de informação, por gerar informações em formatos compatíveis com as diretrizes contábeis, o que contribui para o aspecto da qualidade operacional da empresa, facilitando a tomada de decisão e o levantamento de informações pela Controladoria com maior agilidade, veracidade e segurança.
\end{abstract}

Palavras-chave: Sistema de Informação. Sistema de Informação Contábil. Controladoria.

\section{ABSTRACT}

With the advent of Accounting Information Systems (SICs), paper accounting has lost ground, and the accountant has ceased to be just a bookkeeper, becoming a key player in decision making. With a fully globalized economy, decisions need to be made instantly to ensure the smooth development of business activities, optimizing the economic outcome. SICs have become a means to achieve this goal through the efficient control of management information. The present study aimed to identify the influence of SICs as an instrument to support the generation of reliable information by the Control department. This is a qualitative study with bibliographical and documentary research methodologies, also through a case study in a civil construction company that sought to capture the employees' perception about the use of SIC as a support tool and its role in the accounting information processing within the organization. We concluded that SICs differentiate from other information systems, since they generate information in formats that are compatible with the accounting standards, which contributes to the company's operational quality and facilitates decision making and information gathering by the Control department, with greater agility, veracity and security.

Keywords: Information System. Accounting Information System. Controllership.

Recebido em: 28-08-2016 Aceito em: 07-02-2017

\section{INTRODUÇÃO}

Desde o início da década de noventa, estudos de governança corporativa (GC) têm sido realizados com o intuito de estabelecer novos modelos de gestão definidos a partir da necessidade de alcance de objetivos corporativos alinhados às expectativas das partes interessadas e, mais recentemente, com foco no desenvolvimento sustentável do planeta. Grandes organizações em todo o mundo utilizam esse modelo de gestão para garantir os resultados econômicos esperados por seus acionistas e/ou partes interessadas, por meio de um corpo executivo em condições de administrá-los de acordo com os objetivos estratégicos definidos

\footnotetext{
* Mestre em Economia de Empresas pela Fead/MG. Graduado em Ciências Contábeis pela Pontifícia Universidade Católica de Minas Gerais.

"Professor da Pontifícia Universidade Católica de Minas Gerais. Mestrando em Educação pela Pontifícia Universidade Católica de Minas Gerais.

"** Mestrando em Ciências Contábeis pela Universidade Federal de Minas Gerais.

Doutorando em Educação pela Universidade de Trás-os-Montes Alto Douro (UTAD)/Portugal, Mestre pela Fundação Pedro Leopoldo no Mestrado Profissional em Administração - MPA.
} 
por conselhos de administração. A gestão corporativa, em sua essência, é baseada em quatro pilares (prestação de contas, conformidade, transparência e justiça) e tem sua forma de governo estabelecida para que a gestão do corpo executivo ocorra em função dos objetivos estratégicos definidos pelos acionistas e/ou partes interessadas (ESTEVAM; GUIMARÃES; SOUZA NETO, 2014).

A busca por uma maior participação no mercado, em um ambiente competitivo, faz com que as grandes empresas busquem, nos dias atuais, obter o retorno almejado e se manterem no mercado. Assim, essas empresas necessitam de controles eficientes para que os gestores possam estar a par do que acontece na empresa, podendo então tomar suas decisões em momento oportuno.

Nesse contexto, está inserida a Controladoria. Oliveira, Perez Jr. e Silva (2004) a conceituam como o departamento responsável pelo projeto, pela elaboração, implementação e manutenção do sistema integrado de informações operacionais, financeiras e contábeis de determinada entidade com ou sem finalidades lucrativas. A Controladoria é considerada por muitos autores como o atual estágio evolutivo da Contabilidade e tem se tornado parte da alta administração, participando da formulação e da implementação de estratégias, cabendo-lhe a tarefa de traduzir o plano estratégico em termos de medidas operacionais e administrativas (ATKINSON et al. 2000; GARRISON; NOREEN, 2011 apud LUNKES; GASPARETTO; SCHNORRENBERGER, 2010).

A Controladoria pode ser definida, então, como a unidade administrativa responsável pela utilização de todo o conjunto da Ciência Contábil dentro da empresa (PADOVEZE, 2009). Consiste em um corpo de doutrinas e conhecimentos relativos à gestão econômica e pode ser visualizada sob dois enfoques: primeiro, como órgão administrativo com missão, funções e princípios definidos no modelo de gestão do sistema empresa; segundo, como uma área do conhecimento humano com fundamentos, conceitos, princípios e métodos oriundos de outras ciências (MOSIMANN; FISCH, 1999).

Assim, segundo Catelli (2001), a Controladoria não pode ser vista como um método ou uma forma de fazer, deve ser compreendida tanto como um ramo do conhecimento cujo propósito é estabelecer as bases conceituais, quanto como um órgão administrativo responsável pela propagação do conhecimento, da modelagem e implantação do sistema de informação.

O sistema de informação é um conjunto de recursos humanos, materiais, tecnológicos e financeiros agregados segundo uma sequência lógica para o processamento de dados e tradução em informações, para, com seu produto, permitir às organizações o cumprimento de seus objetivos principais (PADOVEZE, 2010).

Pesquisas que abordam especificamente o Sistema de Informação Contábil ainda são escassas. Ao buscar estudos sobre o tema na Biblioteca Digital de Teses e Dissertações (BDTD), utilizando o descritor "sistema de informação contábil", obteve-se uma amostra de 105 estudos, distribuídos nas seguintes proporções:

TABELA 1 - Pesquisa bibliométrica BDTD

\begin{tabular}{c|c|c|c|c|}
\hline \multirow{2}{*}{ Descritor } & \multicolumn{2}{|c|}{ Tipo } & \multicolumn{2}{c|}{ Idiomas } \\
\cline { 2 - 5 } & Tese & Dissertação & Português & Espanhol \\
\hline Sistema de informação contábil & 12 & 93 & 91 & 14 \\
\hline
\end{tabular}

FONTE: Elaborado pelos autores com dados extraídos de BDTD (2016).

Dentre os estudos encontrados, por estar mais próximo da proposta desta pesquisa, destacamos o de Piontkewicz (2014), que trata da importância do Sistema de Informação Contábil Gerencial (SICG) nas organizações. A pesquisa teve como objetivo principal investigar as contribuições da Contabilidade como Sistema de Informação Gerencial na gestão do Capital Intelectual em uma organização. Para tanto, adotouse um estudo de caso único como estratégia de pesquisa, aplicado em uma indústria de bens de consumo presente no mercado há mais de 85 anos, obtendo como evidências que a inserção de variáveis do Capital Intelectual no SICG possibilita uma uniformização do entendimento sobre o assunto por todos os gestores da empresa.

Outro estudo de destaque que evidenciou o papel da informação contábil foi o de Ferreira (2013), que teve como objetivo investigar o uso das ferramentas contábeis e gerenciais nos processos decisórios de gestores em uma produtora de camarão localizada em Barra de Serinhaém, Pernambuco. Os resultados da pesquisa evidenciaram que a organização não utilizava todos os atributos da Contabilidade gerencial (ferramenta contábil gerencial) devido à recorrente centralização de informações pela alta direção, fato possivelmente decorrente do caráter familiar da empresa. Além disso, foram constatadas falhas nos processos operacionais do setor administrativo no que concerne à precisão e tempestividade das informações, o que afetava negativamente o processo de tomada de decisão dos gestores.

Já o estudo de Dantas (2009) buscou investigar quais variáveis relacionadas ao perfil do gestor e/ou estrutura do negócio podem explicar a opção pelo uso da informação contábil nas indústrias do polo calçadista de Campina Grande-PB, haja vista este ser formado basicamente por pequenas indústrias. Os 
resultados da pesquisa apontaram as seguintes variáveis: quantidade de modelos de calçados produzidos, ou seja, quanto maior o número de modelos produzidos pela indústria, maior será a opção pelo uso da informação contábil; o porte da indústria; e o grau de escolaridade do gestor.

No estudo de Caldas (2014), realizou-se uma pesquisa em empresas do setor de informática localizadas na região metropolitana de Belo Horizonte, que constituíram sua unidade de análise. $O$ estudo teve caráter descritivo e abordagem qualitativa. A coleta dos dados foi realizada por meio de entrevistas semiestruturadas, e a pesquisa procurou descrever como ocorre o processo de tomada de decisão e qual é o papel dos Sistemas de Informações Gerenciais (SIG) nas diversas etapas do processo de tomada de decisão, na visão dos gestores; investigar como os Sistemas de Informações Gerenciais atuam nos processos decisórios e podem trazer resultados para as empresas; e verificar as dificuldades dos Sistemas de Informações Gerenciais nos processos de tomada de decisão. A pesquisa revelou que os gerentes das empresas do setor de informática percebem a importância da utilização do SIG nos processos de tomada de decisão, destacando os seguintes resultados: melhoramento no processo de compra, qualidade dos serviços, ações corretivas, perfil dos clientes, presteza, clareza, atendimento qualificado, competitividade, crescimento da organização com novos clientes, agilidade e desempenho dos serviços.

Entre outros estudos relevantes está o de Amâncio (2011), que teve como objetivo analisar a relação dos impactos gerados pelo ERP nas organizações paranaenses do segmento da indústria e serviços, e os fatores que motivaram a sua adoção. Destaca-se também o estudo de Poncio (2013), que estudou os custos na administração pública, tendo o escopo de pesquisar como o Sistema de Informação de Custos do Governo Federal pode contribuir para a produção de informações gerenciais para subsidiar a tomada de decisão pelos gestores da Polícia Federal .

Finalmente, temos o estudo de Oliveira (2004), que evidencou como a administração das pequenas empresas faz uso das informações contábeis (por meio do Sistema de Informação Contábil integrado numa filosofia ERP) em seus processos de tomada de decisão. O objetivo geral foi respondido pela pesquisa de campo desenvolvida junto às micros e pequenas empresas industriais do estado do Paraná cadastradas no CIN/FIEP (Centro Internacional de Negócios da Federação das Indústrias do Estado do Paraná). A pesquisa mostrou que essas empresas utilizam as informações disponibilizadas pelo Sistema de Informação Contábil para atendimento tanto às necessidades administrativas de cunho fiscal quanto às de cunho gerencial, com uma pequena vantagem para a gerencial.

Por fim, o estudo de Fernandes (2012) teve como objetivo investigar a utilização da informação contábil no processo de prestação de contas (Accountability) aos acionistas/proprietários de hotéis no Brasil. Os resultados apontaram que as informações contábeis utilizadas no processo de prestação de contas eram oriundas principalmente da DRE (Demonstração do Resultado do Exercício), do Balanço Patrimonial, do Relatório Orçamentário, da Demonstração de Fluxo de Caixa e do Controle Patrimonial, por ordem de prioridade. Porém, boa parte das informações geradas pela Contabilidade é insuficiente para subsidiar o processo de prestação de contas. Sinaliza-se, ainda, que os gestores têm dificuldades em obter/produzir informações para elaboração do relatório de prestação de contas porque as informações contábeis são recebidas tardiamente, não são confiáveis e o sistema de informações contábil é deficiente, causando principalmente transtornos ou dificuldades aos gestores. Para a prestação de contas (Accountability) aos acionistas/proprietários, os gestores utilizam como principal meio de comunicação o relatório periódico inferior a um ano.

Portanto, tal como exposto, observa-se que os estudos que evidenciam a aplicabilidade da informação contábil como instrumento de apoio à tomada de decisão enfocam os atores envolvidos mais diretamente com esse processo de tomada de decisão das companhias, como gestores e administradores. Assim, com base nesse contexto e enfocando os colaboradores de níveis inferiores em uma organização, isso é, aqueles que não estão envolvidos em cargos estratégicos, o presente estudo objetivou responder à seguinte indagação: qual a influência do sistema de informação contábil como instrumento de apoio à geração de informações fidedignas pela Controladoria?

O diferencial desta pesquisa é o fato de realizar uma análise da percepção dos colaboradores considerados mais operacionais, ou seja, que não estão diretamente ligados ao processo decisório da empresa, sendo eles responsáveis, muitas vezes, por somente alimentar o SIC com informações fidedignas que devem ser capazes de nortear de forma eficiente as tomadas de decisões das empresas.

Portanto, o estudo buscou, por meio da resposta à inquietação principal, evidenciar se existe a necessidade de uma cultura organizacional mais efetiva e de conscientização desses colaboradores menos engajados - ou menos conscientes - com as necessidades da organização, ampliando o entendimento por parte dos gestores e dos profissionais que atuam na área da Contabilidade, em geral, sobre os fatores que podem influenciar a eficiente implantação e utilização do SIC ao nível da disponibilidade de informação fidedigna para a tomada de decisões.

Dessa forma, proporciona-se aos acadêmicos, sejam eles da área financeira, contábil ou administrativa, um entendimento dos empecilhos relativos ao pessoal envolvido no projeto de implantação e eficiente adoção de um SIC a que as organizações estarão sujeitas. 


\section{REVISÃO DA LITERATURA}

\subsection{A importância do Sistema de Informação Contábil (SIC)}

O Sistema de Informação Contábil (SIC) pode ser entendido como um instrumento que coleta, processa e transforma os dados em informações em forma de relatórios contábeis destinados à administração, ao fisco e aos demais usuários externos interessados. "Os SICs são um tipo especial de sistema de informações que fornecem informações sobre processos e eventos de negócio que afetam a organização" (MOSCOVE; SIMKIN; BAGRANOFF, 2002, p. 22). Para isso, o SIC fundamenta-se na geração de informações para os vários níveis das empresas, suprindo a necessidade de vários usuários, principalmente dos gestores envolvidos diretamente na tomada de decisões.

O SIC, a princípio, era utilizado para alcançar os objetivos da produtividade e da lucratividade, capacitando as pessoas a alcançar resultados mais rápidos e de menor custo (DELOITTE, 1998 apud ALBERTON, LIMONGI; KRUEGER, 2004). Hoje, as redes de informação têm avançado significativamente, capacitando contadores, fornecedores e clientes na comunicação, como a Internet, por exemplo. A informação e o conhecimento são a chave para o sucesso, e há necessidade real de processar a informação e transformá-la em conhecimento, que pode ser usado para conquistar as oportunidades oferecidas pelo mercado (SILVA; CRUZ; SOUZA E SILVA, 2011). Padoveze (2010) destaca que a necessidade da informação é determinada pelos usuários finais dessa informação, por seus consumidores. Assim, a informação deve ser construída para atender a esses consumidores, e não para atender aos contadores, o que se refere ao tratamento dessa informação.

Dessa forma, o SIC precisa ser utilizado de forma alinhada à organização para fornecer as informações de que seus grupos internos precisam, de modo que os administradores devem estar conscientes de que os sistemas de informação podem alterar significativamente a vida da organização, e por isso os atores envolvidos nesse processo de utilização do SIC, desde a coleta até a disseminação dos dados, devem estar alinhados com os objetivos da empresa, pois essa informação é que alimentará os gestores e administradores em sua tomada de decisão, portanto sua fidedignidade é crucial (LAUDON; LAUDON, 2004).

Isso exposto, vale citar o entendimento de Moscove, Simkin e Bagranoff (2002), que postulam que um sistema de informações é um conjunto de subsistemas inter-relacionados que funcionam em conjunto para coletar, processar, armazenar, transformar e distribuir informações para fins de planejamento, tomada de decisões e controle. Nesse sentido, os autores apresentam o seguinte modelo para explicar o funcionamento dos sistemas de informação.

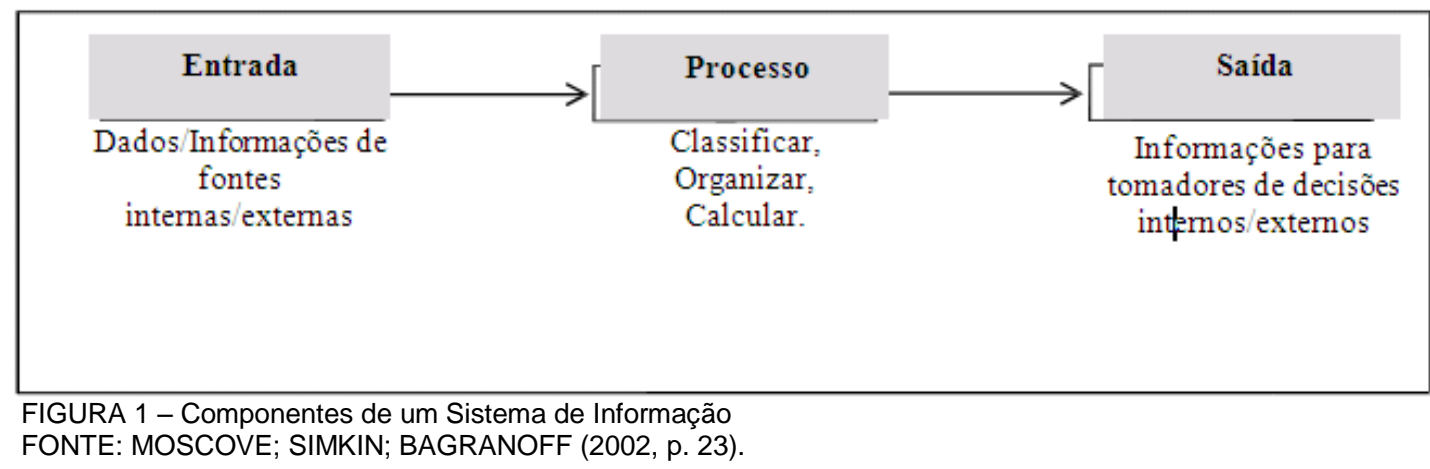

A partir da ilustração, vemos que o SIC é o instrumento que coleta, processa e transforma os dados em informações na forma de relatórios contábeis destinados à administração, ao fisco e aos demais usuários internos e externos da empresa, oferecendo primazia quanto ao atendimento de aspectos operacionais e táticos, primordialmente com informações estruturadas e algumas informações semiestruturadas. Um software contábil bem estruturado e administrado é fundamental no controle e no processo decisório de uma organização, pois possibilita a emissão de relatórios com maior segurança em tempo oportuno sobre as informações geradas (MOSCOVE; SIMKIN; BAGRANOFF, 2002).

Gil, Biancolino e Borges (2010) destacam que o sistema de informação contábil (SIC) pode ser integrado a outros sistemas de informações, principalmente os que dizem respeito aos fatores externos, propiciando informações de extrema relevância para os objetivos estratégicos da empresa. Os autores afirmam ainda que o sistema de informação contábil (SIC) possui características de consolidar os demais sistemas de informações de outras áreas da empresa, inclusive os de missões operacionais (compras, contas a pagar, contas a receber, tesouraria, faturamento, entre outros), os quais são subsistemas daquele. 


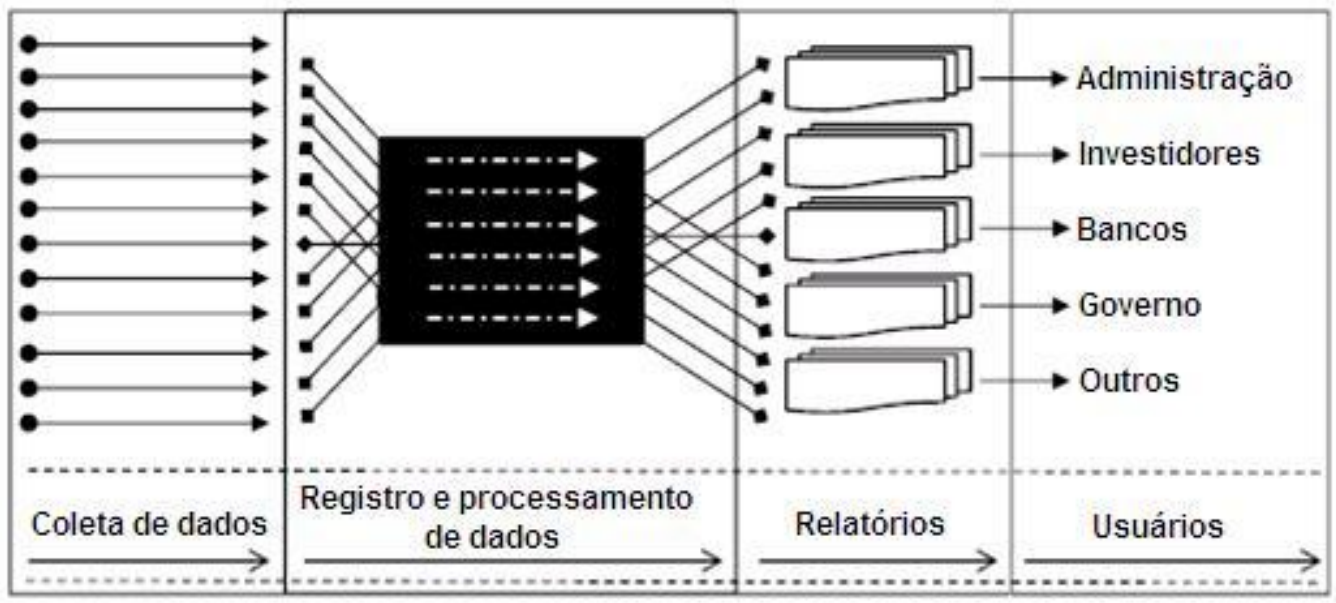

FIGURA 2 - Abrangência do Sistema de Informação Contábil (SIC)

FONTE: Adaptado de GIL; BIANCOLINO; BORGES (2010, p. 10).

Gil, Biancolino e Borges (2010, p. 10-11) definem que os "sistemas de informações fazem parte de um sistema maior, o sistema da empresa. Dessa forma, os componentes organizacionais e as pessoas não podem ser considerados isoladamente". Nesse sentido, os autores esclarecem que "cabe lembrar também que todo sistema é um conjunto de partes que integram para atingir um determinado objetivo. Logo, a tecnologia não pode, sozinha, compor um sistema de informações e se transformar em um fim em si mesma" (GIL; BIANCOLINO; BORGES, 2010, p. 11), daí a importância do alinhamento de todos os colaboradores envolvidos na utilização do SIC de ponta a ponta dentro da organização.

Uma vez que ocorre um fluxo de informação dos subsistemas para o SIC (compras, contas a pagar, contas a receber, tesouraria, faturamento, entre outros), todas essas informações contábil-financeiras são úteis para o processo decisório. Assim, para aperfeiçoar a utilização do SIC, as empresas dividem esses sistemas em duas grandes áreas, quais sejam: as áreas legal/fiscal e gerencial. A consolidação das informações contábeis resulta das ações de coleta de dados, registro e processamento destes, no sentido de consolidar todas as informações em um só processo, demonstrando, de forma estruturada, o desempenho e os resultados econômico-financeiros das organizações por meio de relatórios aos usuários internos e externos à organização.

\subsection{A Controladoria como sistema de gestão}

A Controladoria pode ser entendida como um mecanismo de poder estratégico quando se busca a produtividade econômica, uma das condições mínimas para a continuidade do negócio empresarial. Diante disso, é o "departamento responsável pelo projeto, elaboração, implementação e manutenção do sistema integrado de informações operacionais, financeiras e contábeis de determinada entidade, sendo considerada por muitos autores como o atual estágio evolutivo da Contabilidade" (OLIVEIRA; PEREZ JR.; SILVA, 2008, p. 13). Procura desempenhar, junto à organização empresarial, o controle com eficiência, qualidade, inovação, e priorizar a geração de indicadores de desempenho para melhorar continuamente a utilização de recursos e a execução das atividades de trabalho que criam valor à empresa e aos seus clientes.

Figueiredo e Caggiano (2008) destacam que a missão da Controladoria é zelar pela continuidade da empresa, assegurando a otimização do resultado global. Assim, a Controladoria representa a propriedade empresarial de instrumentalização para a gestão de vantagens competitivas, pois, atuando como mecanismo de retroalimentação na melhoria do desempenho de processos e dos seus respectivos produtos, ela passa a ser fundamental na estratégia, nas ações competitivas e de melhoria da organização empresarial, otimizando os resultados econômicos da empresa por meio da definição de um sistema de informações baseado no modelo de gestão.

Siegel e Kulesza (1996), citados por Lunkes, Gasparetto e Schnorrenberger (2010), asseveram que a Controladoria tem se especializado no apoio à decisão. Tem a função de garimpar a informação, transformando-a de tal forma que auxilie e facilite a tomada de decisão das demais áreas. Para Oliveira, Perez Jr. e Silva (2004), o papel da Controladoria, portanto, é assessorar as diversas gestões da empresa, fornecendo mensurações das alternativas econômicas, e, por meio de visão sistêmica, integrar informações e reportá-las para facilitar o processo decisório.

Para que a Controladoria exerça suas funções, com vistas a cumprir sua missão e para que seus objetivos sejam alcançados, há necessidade de profissionais que possuam certos atributos para assegurar que isso ocorra. Ludícibus (1986), citado por Moura e Beuren (2000, p. 63), afirma que a característica 
fundamental de um contador gerencial é "saber tratar, refinar e apresentar, de maneira clara, resumida e operacional, dados esparsos contidos nos registros da contabilidade financeira, de custos, entre outras, bem como juntar tais informes com outros conhecimentos não especificamente ligados à área contábil para suprir a administração em seu processo decisório". Para Garrison (1976), citado por Mosimann e Fisch (1999, p. 89), "o controller faz parte da cúpula administrativa e participa ativamente nos processos de planejamento e controle empresarial".

\section{METODOLOGIA DE PESQUISA}

A utilização e a especificação dos métodos utilizados para o desenvolvimento de pesquisas são essenciais, pois atribuem caráter científico aos estudos, distinguindo-os das demais formas de conhecimento. As pesquisas acadêmicas classificam-se quanto aos objetivos, aos procedimentos e à abordagem do problema (MALHOTRA, 2006).

Quanto à abordagem do problema, este estudo se enquadra como pesquisa qualitativa. Raupp e Beuren (2004, p. 92) explicam que "na pesquisa qualitativa concebem-se análises mais profundas em relação ao fenômeno estudado". A pesquisa qualitativa auxilia na identificação e no entendimento das questões que são relevantes ao estudo científico realizado. Utiliza-se esse tipo de pesquisa para verificar a extensão total da resposta ou das opiniões colhidas sobre o assunto e a população pesquisada, trabalhando, assim, com o universo de significados, motivos, aspirações, crenças, valores e atitudes, o que corresponde a um espaço mais profundo das relações, dos processos e dos fenômenos que não podem ser reduzidos à operacionalização de variáveis. Em virtude da sua caracterização, "a pesquisa qualitativa é criticada por seu empirismo, pela subjetividade e pelo envolvimento do emocional do pesquisador" (MINAYO, 2001, p. 14).

Nesse contexto, a respeito da importância da neutralidade do pesquisador, Matias-Pereira (2012, p. 60) ressalta: "[...] na busca de fazer a ciência é fundamental ter em mente a ideia da neutralidade do pesquisador. Ao se investigar e pesquisar os fatos e os fenômenos, o investigador não deve interferir, mas deixar que a 'verdade' surja naturalmente".

Quanto aos objetivos adotados para a realização deste artigo, utilizou-se a pesquisa descritiva, que exige do investigador uma série de informações sobre o que deseja pesquisar. Esse tipo de estudo pretende descrever os fatos e fenômenos de determinada realidade (TRIVIÑOS, 1987).

Os procedimentos técnicos utilizados para o desenvolvimento deste projeto foram seguidos à luz de uma ampla pesquisa bibliográfica, elaborados a partir de material já publicado. Essa pesquisa foi feita a partir do levantamento dos referenciais teóricos já analisados e publicados por meios escritos e eletrônicos, como livros, artigos científicos, páginas de web sites.

Para evidenciar, na prática, e responder ao objetivo da pesquisa, foi realizado um estudo de caso, que pode ser caracterizado como um estudo de uma entidade bem definida, como um programa, uma instituição, um sistema educativo, uma pessoa ou uma unidade social, visando conhecer em profundidade o como e o porquê de uma determinada situação que se supõe ser única em muitos aspectos, procurando descobrir o que há nela de mais essencial e característico.

O pesquisador não pretende intervir sobre o objeto a ser estudado, mas revelá-lo tal como ele o percebe. $O$ estudo de caso pode ocorrer de acordo com uma perspectiva interpretativa, que procura compreender como é o mundo do ponto de vista dos participantes, ou uma perspectiva pragmática, que visa simplesmente apresentar uma perspectiva global, tanto quanto possível completa e coerente, do objeto de estudo do ponto de vista do investigador (FONSECA, 2002). Como estratégia, adotamos o estudo de caso como procedimento metodológico, no qual visamos conhecer um pouco mais da realidade organizacional de uma empresa do ramo de construção civil quanto à utilização do Sistema de Informação Contábil por seus colaboradores.

No caso, esse estudo de caso foi aplicado em uma construtora sediada na região metropolitana de Belo Horizonte-MG, e o motivo da escolha desse segmento da economia foi devido à relevância que possui na economia mineira. Conforme é frisado por Teixeira, Gomes e Silva (2011), em se tratando da economia mineira, verificou-se na literatura consultada que poucos trabalhos se preocupam em estabelecer o papel estratégico da indústria da construção para a sustentação do desenvolvimento econômico e social do estado de Minas Gerais, com ênfase nas suas interligações com outras atividades econômicas e nos seus efeitos de transbordamento sobre a produção, a renda, o emprego e os tributos estaduais.

Portanto, entender e dar subsídios para a gestão interna quanto aos fatores intrínsecos desse segmento se torna importante. Outro fator que motivou a escolha desse ramo de atividade foi a acessibilidade, ou seja, a facilidade na aplicação dos questionários para se obterem as evidências necessárias para se responder à inquietação desta pesquisa. Marconi e Lakatos (2003) consideram que o questionário é "um instrumento de coleta de dados, constituído por uma série ordenada de perguntas, que devem ser respondidas por escrito e sem a presença do entrevistador". Os questionários foram aplicados aos colaboradores no primeiro semestre de 2016, ou seja, de janeiro a junho. 


\subsection{Cenário de Estudo}

Para ilustrar e detectar a influência do Sistema de Informação Contábil como instrumento de apoio à geração de informações fidedignas pela Controladoria, foi realizado um estudo de caso em uma construtora, sociedade anônima de capital fechado, estabelecida na cidade do Rio de Janeiro-RJ, que tem sua sede administrativa em Belo Horizonte-MG e filiais em quase todo o território nacional.

A companhia tem como principais objetivos sociais a exploração, implantação e execução de obras de construção civil contratadas por entidades de direito público e privado, além de comércio, atividades agropecuárias, execução de serviços de limpeza pública e industrial, exploração de bens públicos mediante concessão da Administração Pública Direta e Indireta, locação de máquinas e equipamentos, incorporação, compra, venda e locação de imóveis e participação em outras sociedades.

O capital social, que gira próximo a $R \$ 61$ milhões, possui dois acionistas, sendo um deles uma Holding. Possui cerca de mil funcionários, com receita anual média de aproximadamente $R \$ 323$ milhões. $A$ empresa possui cinco membros em funções estratégicas, que são: Diretor Superintendente, Diretor Administrativo, Diretor Financeiro, Diretor Técnico e Controller.

\section{ANÁLISE DOS RESULTADOS}

A pesquisa foi realizada com 29 (vinte e nove) funcionários que atuam na sede e nas demais unidades da empresa, entrevistados aleatoriamente em alguns dos setores da organização por meio de questionário fechado composto de 15 (quinze) questões aplicadas pessoalmente na empresa e também encaminhadas via correio eletrônico. Após a coleta dos dados, passou-se então para a tabulação por meio de planilhas eletrônicas e interpretações.

A tabela a seguir apresenta informações quanto ao setor de atuação dos respondentes.

TABELA 2 - Setor de atuação dos entrevistados

\begin{tabular}{lcc}
\hline \multicolumn{1}{c}{ Setor de atuação } & Frequência & $\%$ \\
\hline Administrativo & 6 & $21 \%$ \\
Contábil e Fiscal & 3 & $10 \%$ \\
Faturamento & 3 & $10 \%$ \\
Suprimentos & 8 & $28 \%$ \\
Tecnologia da Informação & 3 & $10 \%$ \\
Departamento Pessoal & 3 & $10 \%$ \\
Outro(s) & 3 & $10 \%$ \\
Total & 29 & $100 \%$ \\
\hline
\end{tabular}

FONTE: Dados da pesquisa (2016).

Verificou-se uma predominância no setor de setor de Suprimentos, com $28 \%$, e no Administrativo, com $21 \%$. Nos demais setores, manteve-se um percentual fixo de $10 \%$.

Outro aspecto questionado refere-se à formação acadêmica dos entrevistados, cujos dados são apresentados na tabela a seguir.

TABELA 3 - Formação dos colaboradores

\begin{tabular}{lcc}
\hline \multicolumn{1}{c}{ Escolaridade } & Frequência & $\%$ \\
\hline Ensino Fundamental/Médio & 7 & $24 \%$ \\
Curso Técnico Profissionalizante & 2 & $7 \%$ \\
Ensino Superior incompleto & 11 & $38 \%$ \\
Ensino Superior completo & 7 & $24 \%$ \\
Pós-graduação & 2 & $7 \%$ \\
Total & 29 & $100 \%$ \\
\hline
\end{tabular}

FONTE: Dados da pesquisa (2016).

Foi evidenciado que $38 \%$ dos respondentes possuem curso superior incompleto, $24 \%$ possuem curso superior completo, $24 \%$ têm o ensino fundamental/médio, completo ou incompleto, $7 \%$ possuem curso técnico profissionalizante e apenas $7 \%$ possuem nível de pós-graduação. Verificou-se que, mesmo com 
uma preocupação acerca da formação acadêmica-profissional, ainda temos um número expressivo de pessoas que possuem apenas ensino fundamental/médio, podendo refletir em uma menor aceitabilidade frente a um processo de mudança e de inovação tecnológica.

O próximo dado apurado foi o tempo de atuação na empresa, cujos resultados são mostrados na tabela a seguir.

TABELA 4 - Tempo de atuação na empresa

\begin{tabular}{lcc}
\hline \multicolumn{1}{c}{ Tempo } & Frequência & $\%$ \\
\hline Menos de 01 ano & 7 & $24 \%$ \\
01 a 03 anos & 5 & $17 \%$ \\
03 a 05 anos & 5 & $17 \%$ \\
Acima de 05 anos & 12 & $41 \%$ \\
Total & 29 & $100 \%$ \\
\hline
\end{tabular}

FONTE: Dados da pesquisa (2016).

Verificou-se que $41 \%$ dos respondentes atuam há mais 5 anos na empresa, $24 \%$ podem ser considerados como recém-contratados e os demais funcionários estão nas faixas de 1 a 3 anos e de 3 a 5 anos, mantendo-se com percentual fixo de $17 \%$.

Ao informar o tempo de atuação na empresa, consequentemente os respondentes apontaram o tempo de utilização de sistemas de informação na organização.

TABELA 5 - Tempo de utilização dos sistemas de informação na empresa

\begin{tabular}{lcc}
\hline \multicolumn{1}{c}{ Tempo } & Frequência & $\%$ \\
\hline Menos de 1 Ano & 5 & $17 \%$ \\
1 Ano & 2 & $7 \%$ \\
2 Anos & 4 & $14 \%$ \\
3 Anos & 1 & $3 \%$ \\
Mais de 3 Anos & 17 & $59 \%$ \\
Total & 29 & $100 \%$ \\
\hline
\end{tabular}

FONTE: Dados da pesquisa (2016).

Com o resultado apresentado e observando-se os extremos da tabela, pode-se perceber que $59 \%$ dos entrevistados utilizam o sistema de informação há mais de 3 anos, enquanto $17 \%$ têm menos de 1 ano de prática. Já $14 \%$ têm 2 anos de prática no sistema, $7 \%, 1$ ano e $3 \%, 3$ anos. Nota-se que o uso do sistema de informação é fator predominante na atuação dos pesquisados.

$\mathrm{Na}$ sequência, buscou-se levantar, junto aos respondentes, as informações quanto à existência de treinamento para a utilização do sistema de informação da empresa.

TABELA 6 - Existência de treinamento para utilização do sistema de informação da empresa

\begin{tabular}{|c|c|c|}
\hline Recebeu treinamento? & Frequência & $\%$ \\
\hline Sim & 25 & $86 \%$ \\
\hline Não & 4 & $14 \%$ \\
\hline Total & 29 & $100 \%$ \\
\hline
\end{tabular}

FONTE: Dados da pesquisa (2016).

Dos 29 pesquisados, $86 \%$ apontaram que receberam treinamento ao serem inseridos na organização, enquanto $14 \%$, ou seja, apenas 4 entrevistados, informaram que não receberam treinamento. Quando questionados sobre o porquê da ausência de treinamento, uma vez que é prática adotada pela empresa, estes responderam que já atuavam na área e eram conhecedores do sistema de informação contábil utilizado pela organização.

Diante do questionamento anterior sobre a existência de treinamento para utilização do sistema de informação contábil da empresa, buscou-se levantar, junto aos respondentes, dados quanto ao período do treinamento oferecido. 
TABELA 7 - Período de tempo do treinamento

\begin{tabular}{lcc}
\multicolumn{1}{c}{ Tempo } & Frequência & $\%$ \\
\hline Entre 1 e 6 meses & 24 & $96 \%$ \\
Entre 7 e 12 meses & 1 & $4 \%$ \\
Total & 25 & $100 \%$
\end{tabular}

FONTE: Dados da pesquisa (2016).

Dos 25 entrevistados que receberam treinamento, 96\% apontaram que este teve duração de 1 a 6 meses, enquanto para $4 \%$ este durou entre 7 a 12 meses, ou seja, uma pequena parcela recebeu uma carga maior de treinamento.

Quando questionados acerca de um possível esclarecimento sobre o fato, o colaborador que recebeu treinamento entre 7 a 12 meses argumentou que já havia atuado no setor administrativo e atualmente atua no setor de Departamento Pessoal. É importante ressaltar que houve colaboradores que não responderam a essa questão, uma vez que eram profissionais já atuantes na área e conhecedores do sistema de informação contábil utilizado pela organização.

O próximo passo foi verificar quais eram os módulos de sistemas de informações contábeis (SIC) disponíveis para os colaboradores na empresa.

TABELA 8 - Módulos do SIC utilizados

\begin{tabular}{lcc}
\hline \multicolumn{1}{c}{ Módulos } & Frequência & $\%$ \\
\hline Controle Financeiro & 7 & $13 \%$ \\
Escrituração e Controle Fiscal & 4 & $7 \%$ \\
Faturamento, Estoque, Compras e & 26 & $46 \%$ \\
Contratos & 2 & $4 \%$ \\
Contabilidade Gerencial & 5 & $9 \%$ \\
Folha de Pagamento & 12 & $21 \%$ \\
Outro(s) & 56 & $100 \%$ \\
Total & &
\end{tabular}

De acordo com a pesquisa realizada, $46 \%$ utilizam os módulos Faturamento, Estoque, Compras e Contratos, cuja característica funcional é facilitar ao máximo as operações e rotinas das áreas de faturamento, estoque, compras e contratos no sistema de informação. Por outro lado, $21 \%$ utilizam outros módulos não mencionados na pesquisa. Podemos destacar um sistema utilizado pelo pessoal de controle de manutenção e pelo pessoal atuante nos departamentos ligados à engenharia $-13 \%$ utilizam o módulo Controle Financeiro, que visa facilitar ao máximo as operações e rotinas da área financeira das empresas, 9\% utilizam o módulo Folha de Pagamento, que visa permitir a realização das rotinas de processamento da folha de pagamento, 7\% utilizam o módulo Escrituração e Controle Fiscal, que visa oferecer segurança e agilidade para as diversas operações fiscais da empresa, como emissão dos livros fiscais, emissão de guias para recolhimento e apuração de impostos, reduzindo em muito o tempo necessário para o fechamento das rotinas fiscais, representando rapidez e economia de tempo. Outros $4 \%$ utilizam o módulo Contabilidade Gerencial, desenvolvido para gerenciamento e administração das rotinas contábeis das empresas, atendendo de forma atual e completa às necessidades e exigências da legislação vigente. Os módulos Controle de Patrimônio e Automação de Ponto estão passando por fase de implantação, motivo pelo qual não foram citados.

A próxima questão teve o intuito de apurar quais são as ferramentas mais utilizadas pelos entrevistados. 
TABELA 9 - Ferramentas de gestão do sistema de informação mais utilizadas

\begin{tabular}{lcc}
\hline Quais ferramentas de gestão oferecidas pelo & Frequência & $\%$ \\
sistema de informação você mais utiliza? & 27 & $18 \%$ \\
\hline Geração de Relatórios & 16 & $11 \%$ \\
Geração de Planilhas & 17 & $12 \%$ \\
Importação de informações & 17 & $12 \%$ \\
Exportação de informações & 14 & $10 \%$ \\
Consultas SQL[1] & 3 & $2 \%$ \\
Escrituração fiscal das atividades & 6 & $4 \%$ \\
Apuração e emissão de guias & 3 & $2 \%$ \\
Apuração e geração da folha de pagamento & 4 & $3 \%$ \\
Controle de contas a pagar e receber & 6 & $4 \%$ \\
Atendimento ao fisco (declarações, & 3 & $2 \%$ \\
demonstrativos) & 2 & $1 \%$ \\
Emissão de Balancetes/Balanço Patrimonial & 2 & $18 \%$ \\
Emissão de Razão & 26 & $100 \%$ \\
Emissão de Diário & 146 & \\
Outra(s) & & \\
Total & &
\end{tabular}

FONTE: Dados da pesquisa (2016).

De acordo com a pesquisa realizada, constatou-se que a maioria dos entrevistados utiliza as ferramentas de gestão oferecidas pelo sistema de informação, podendo-se destacar aquela relacionada à geração de relatórios, com $18 \%$.

O próximo objeto de pesquisa foi verificar se os entrevistados utilizam informações contábeis para tomar decisões.

TABELA 10 - Utiliza sistema de informação contábil para tomar decisões?

\begin{tabular}{lcc}
\hline $\begin{array}{l}\text { Utiliza o SIC como apoio para as tomadas de } \\
\text { decisões? }\end{array}$ & Frequência & $\%$ \\
\hline Sim & 3 & $10 \%$ \\
Não & 16 & $55 \%$ \\
Às vezes & 10 & $34 \%$ \\
Total & 29 & $100 \%$ \\
\hline
\end{tabular}

FONTE: Dados da pesquisa (2016).

Dos 29 entrevistados, 55\% afirmam que não utilizam sistema de informação contábil como apoio para tomar decisões, enquanto $34 \%$ o utilizam às vezes e apenas $10 \%$ o utilizam efetivamente. Um dos possíveis motivos para a baixa aderência ao uso do SIC como suporte para a tomada de decisões pode ser o fato de que os entrevistados, em sua maioria, não ocupam cargos estratégicos dentro da organização.

Os entrevistados foram também solicitados a dar sua opinião acerca do motivo pelo qual a empresa teria adotado o sistema de informação. O resultado é apresentado na tabela a seguir.

TABELA 11 - Motivos pelos quais a empresa passou a utilizar o sistema de informação, na opinião dos colaboradores

\begin{tabular}{lcc}
\hline $\begin{array}{l}\text { Em sua opinião, qual o principal motivo que levou a } \\
\text { empresa a utilizar o sistema de informação? }\end{array}$ & Frequência & $\%$ \\
\hline $\begin{array}{l}\text { Facilidade no planejamento, controle, avaliação de } \\
\text { desempenho e tomada de decisão. }\end{array}$ & 0 & $0 \%$ \\
$\begin{array}{l}\text { Facilidade de acesso às informações financeiras e } \\
\text { econômicas da empresa. }\end{array}$ & 0 & $0 \%$ \\
$\begin{array}{l}\text { Segurança, confiabilidade e exatidão nos relatórios } \\
\text { oferecidos pela Contabilidade. }\end{array}$ & 0 & $0 \%$ \\
Todos & 29 & $100 \%$ \\
Outro(s) & 0 & $0 \%$ \\
Total & 29 & $100 \%$ \\
\hline
\end{tabular}

FONTE: Dados da pesquisa (2016). 
Percebe-se que o principal motivo que levou a empresa a utilizar um sistema de informação informatizado, na opinião dos entrevistados, é a facilidade no planejamento, controle, avaliação de desempenho, tomada de decisão, facilidade de acesso às informações financeiras e econômicas da empresa, segurança, confiabilidade e exatidão nos relatórios oferecidos pela Contabilidade, ou seja, todos os entrevistados acreditam que a empresa levou em conta todos os motivos apreciados na pesquisa.

Outra concepção apurada na pesquisa foi a eficiência do software para suprir as necessidades no ambiente e na rotina profissional.

TABELA 12 - Capacidade do software em suprir as necessidades, na opinião dos colaboradores

\begin{tabular}{lcc}
\hline O SIC adotado na empresa é capaz de suprir todas & Frequência & $\%$ \\
as suas necessidades? & 2 & $7 \%$ \\
\hline Concordo totalmente & 16 & $55 \%$ \\
Concordo parcialmente & 0 & $0 \%$ \\
Discordo totalmente & 4 & $14 \%$ \\
Discordo parcialmente & 7 & $24 \%$ \\
Indiferente & 29 & $100 \%$ \\
Total & & \\
\hline
\end{tabular}

FONTE: Dados da pesquisa (2016).

Dos 29 entrevistados, 55\% concordam parcialmente que o software utilizado é capaz de suprir todas as necessidades, enquanto $24 \%$ se mantêm indiferentes. Outros $14 \%$ discordam parcialmente, e outros $7 \%$ concordam totalmente.

O próximo tópico apurou a concepção dos colabores acerca da seguinte questão: o SIC atende às necessidades no que tange à geração de relatórios para auxiliar nas tomadas de decisões?

TABELA 13 - Capacidade do SIC em fornecer os relatórios das áreas financeira, tributária e contábil para a tomada de decisões, na opinião dos colaboradores

\begin{tabular}{lcc} 
Em sua opinião, o sistema utilizado pela empresa gera & & \\
todos os relatórios necessários para a tomada de & Frequência & $\%$ \\
decisões, em relação a questões financeiras, tributárias e & & $0 \%$ \\
administrativas? & 0 & $52 \%$ \\
\hline Concordo totalmente & 15 & $0 \%$ \\
Concordo parcialmente & 0 & $0 \%$ \\
Discordo totalmente & 0 & $48 \%$ \\
Discordo parcialmente & 14 & $100 \%$ \\
Indiferente & 29 & \\
Total & &
\end{tabular}

FONTE: Dados da pesquisa (2016).

A pesquisa apontou que $52 \%$ dos 29 entrevistados concordam parcialmente que o sistema utilizado pela empresa gera todos os relatórios necessários para a tomada de decisões nas áreas financeira, tributária e administrativa, contra $48 \%$, que se mantêm indiferentes sobre o assunto.

Sobre a segurança, confiabilidade e rapidez nas informações mensuradas no sistema de informação, tivemos o seguinte retorno por parte dos entrevistados.

TABELA 14 - Nível de segurança, confiabilidade e rapidez nas informações ou relatórios fornecidos pelo sistema, na opinião dos colaboradores

\begin{tabular}{lcc}
\hline $\begin{array}{l}\text { Em sua opinião, o sistema oferece } \\
\text { confiabilidade e rapidez nas informações } \\
\text { fornecidos? }\end{array}$ & Frequência & $\%$ \\
\hline Concordo totalmente & 3 & $10 \%$ \\
Concordo parcialmente & 15 & $52 \%$ \\
Discordo totalmente & 0 & $0 \%$ \\
Discordo parcialmente & 4 & $14 \%$ \\
Indiferente & 7 & $24 \%$ \\
Total & 29 & $100 \%$ \\
\hline
\end{tabular}

FONTE: Dados da pesquisa (2016). 
Verificou-se que $52 \%$ dos 29 entrevistados concordam parcialmente que o sistema da empresa oferece segurança, confiabilidade e rapidez nas informações e relatórios fornecidos. Por outro lado, $24 \%$ se mantêm indiferentes, $14 \%$ discordam parcialmente e, por fim, 10\% concordam totalmente.

No próximo tópico, perguntou-se aos colaboradores se o sistema foi elaborado para atender às demandas da empresa.

TABELA 15 - Aderência do sistema às necessidades da empresa, na opinião dos colaboradores

\begin{tabular}{lcc} 
Em sua opinião, o sistema é elaborado acordo com & Frequência & $\%$ \\
a necessidade da empresa? & 0 & $0 \%$ \\
\hline Concordo totalmente & 15 & $52 \%$ \\
Concordo parcialmente & 0 & $0 \%$ \\
Discordo totalmente & 7 & $24 \%$ \\
Discordo parcialmente & 7 & $24 \%$ \\
Indiferente & 29 & $100 \%$ \\
Total & &
\end{tabular}

FONTE: Dados da pesquisa (2016).

Constatou-se que $52 \%$ dos 29 entrevistados concordam parcialmente que o sistema adotado pela empresa é suficiente para suprir as necessidades desta. Já $24 \%$ se mantêm indiferentes ou discordam parcialmente.

Por fim, foi apurada a concepção dos respondentes no que se refere à satisfação quanto ao conteúdo, à forma e ao tempo na utilização do sistema da empresa.

TABELA 16 - Satisfação com o sistema em termos de conteúdo, forma e tempo na emissão de informações

\begin{tabular}{l|cccccc}
\hline \multirow{2}{*}{ Nível de satisfação } & \multicolumn{2}{c}{ Conteúdo } & \multicolumn{2}{c}{ Forma } & \multicolumn{2}{c}{ Tempo } \\
\cline { 2 - 7 } & Frequência & $\%$ & Frequência & $\%$ & Frequência & $\%$ \\
\hline Muito Satisfatório & 4 & $14 \%$ & 4 & $14 \%$ & 3 & $10 \%$ \\
Satisfatório & 21 & $72 \%$ & 25 & $86 \%$ & 16 & $55 \%$ \\
Pouco Satisfatório & 4 & $14 \%$ & 0 & $0 \%$ & 10 & $34 \%$ \\
Indiferente & 0 & $0 \%$ & 0 & $0 \%$ & 0 & $0 \%$ \\
Total & 29 & $100 \%$ & 29 & $100 \%$ & 29 & $100 \%$ \\
\hline
\end{tabular}

FONTE: Dados da pesquisa (2016).

Ao serem perguntados sobre a qualidade das informações geradas pelo ERP quanto ao conteúdo, à forma e ao tempo, $72 \%$ acreditam que a dimensão do conteúdo é satisfatória e outros $14 \%$ acreditam que a dimensão do conteúdo é muito satisfatória. Por outro lado, 14\% consideram a dimensão do conteúdo pouco satisfatória. Quando questionados sobre a dimensão da forma, $86 \%$ acreditam ser satisfatória e $14 \%$ acreditam ser muito satisfatória. Já acerca da dimensão do tempo, $55 \%$ acreditam ser satisfatória, $34 \%$ acreditam ser pouco satisfatória e $10 \%$ acreditam ser muito satisfatória.

\section{CONCLUSÕES}

No presente artigo, tivemos como preocupação responder à seguinte questão-problema: qual a influência do sistema de informação contábil como instrumento de apoio à geração de informações fidedignas pela Controladoria? Esse objetivo alinha-se com o fato de que, nos últimos anos, vem crescendo a necessidade de novas tecnologias que agilizem os processos decisórios e tornem dinâmica a distribuição de informações a seus usuários.

Nesse contexto, a Controladoria precisou dar um salto rumo à praticidade e modernidade, visando à competitividade e à eficiência. Para acompanhar esse desenvolvimento, o SIC é um grande aliado e tem como objetivo acompanhar as atualizações e promover melhores resultados para a empresa. O SIC é utilizado como instrumento para processamento, gerenciamento e integração das informações contábeis. São inúmeras as vantagens propiciadas pelo seu uso.

O resultado do estudo de caso deste trabalho espelha um pouco dessa realidade, a partir da evidenciação da importância do SIC não só para a Controladoria, mas para os demais departamentos envolvidos diretamente no resultado da empresa. Constata-se a importância do SIC em relação à facilidade no planejamento, controle, avaliação de desempenho e tomada de decisão, facilidade de acesso às 
informações financeiras e econômicas da empresa e segurança, confiabilidade e exatidão nos relatórios oferecidos pela Contabilidade.

Com o estudo de caso realizado em uma empresa do ramo de construção civil, foi possível verificar que, apesar do forte uso da tecnologia disponibilizada aos usuários/colaboradores da empresa, há um grande número destes que não se utilizam desses sistemas como uma ferramenta gerencial/contábil estratégica, mas única e exclusivamente para simples input de informações. Porém, há benefícios do uso do SIC tais como confiabilidade, segurança e eficiência nas informações por ele disponibilizadas. Esse não reconhecimento por parte de alguns colaboradores, de que o SIC é uma importante ferramenta estratégica para a tomada de decisões, está diretamente ligado à própria cultura da empresa, que ainda não estruturou e despertou em seu quadro de funcionários o entendimento de que podem maximizar os resultados com o apoio do SIC.

As evidências obtidas nesta pesquisa podem significar que, além do custo envolvido na implantação de um SIC dentro da organização, existe a necessidade de investir na qualificação dos colaboradores envolvidos na eficiente operação e manutenção de dados dentro da estrutura, garantindo, com isso, o êxito na obtenção de informações fidedignas e tempestivas para auxiliar nas tomadas de decisões.

O estudo fornece subsídios para uma futura reaplicação em outras empresas do mesmo segmento, buscando evidências de fatos correlacionados com os apresentados nesta pesquisa. Pretende ainda contribuir com os profissionais na área para o entendimento da percepção dos colaboradores envolvidos em áreas operacionais das empresas. Para a classe acadêmica, espera-se que o estudo sirva de base para o desenvolvimento de outros tipos de estudos que envolvam o Sistema de Informação Contábil em outros ramos da economia.

\section{REFERÊNCIAS}

ALBERTON, L.; LIMONGI, B.; KRUEGER N. Os reflexos da implantação de um ERP em um escritório de Contabilidade. In: CONGRESSO USP DE CONTROLADORIA E CONTABILIDADE, 4., 2004, São Paulo. Anais eletrônicos... São Paulo: FEA/USP, 2004.

AMÂNCIO, A. J. Análise dos fatores de decisão e impactos gerados pela solução ERP: percepção dos gestores de empresas industriais e de serviços paranaenses. 2011. 188f. Dissertação (Mestrado em Contabilidade) - Universidade Federal do Paraná, Curitiba, 2011.

CALDAS, S. C. O: estudo em empresas do setor de Informática localizadas na região metropolitana de Belo Horizonte. 2014. Papel dos sistemas de informação gerencial no processo de tomada de decisão. 90 f. Dissertação (Mestrado em Administração) - Programa de Pós-Graduação em Administração, Faculdade Novos Horizontes, Belo Horizonte, 2014.

CATELLI, A. (Coord.). Controladoria: uma abordagem da gestão econômica - GECON. 2. ed. São Paulo: Atlas, 2001.

DANTAS, R. F. Um diagnóstico da utilização da informação contábil como suporte à tomada de decisão nas indústrias calçadistas da cidade de Campina Grande-PB. 2009. 91 f. Dissertação (Mestrado em Ciências Contábeis) - Programa Multi-institucional e Inter-Regional de Pós-Graduação em Ciências Contábeis, Universidade de Brasília/UFPB/UFRN, João Pessoa, 2009.

ESTEVAM, R. G. B.; GUIMARÃES, J. B. D. N.; SOUZA NETO, J. Como um ERP promove a governança corporativa numa empresa. Revista Gestão \& Planejamento, v. 15, n. 2, p. 238-260, 2014.

FERNANDES, M. S. A. Potencial de utilização da informação contábil no processo de prestação de contas sob a ótica do mecanismo da governança corporativa: um estudo em hotéis brasileiros. 2012. $234 \mathrm{f}$. Tese (Doutorado em Ciências Contábeis) - Universidade de Brasília, UFPB, UFRN, João Pessoa, 2012.

FERREIRA, T. B. Utilização da informação contábil gerencial na tomada de decisão de gestores de criação de camarão: um estudo em um produtor do Esstado de Pernambuco. 2013. Dissertação (Mestrado em Ciências Contábeis) - Universidade Federal de Pernambuco, Recife, 2013.

FIGUEIREDO, S.; CAGGIANO, P. C. Controladoria: teoria e prática. 4. ed. São Paulo: Atlas, 2008.

FONSECA, J. J. S. Metodologia da pesquisa científica. Fortaleza: UEC, 2002. Apostila.

GIL, A. de L.; BIANCOLINO, C. A.; BORGES, T. N. Sistemas de informações contábeis: uma abordagem gerencial. São Paulo: Saraiva, 2010.

LAKATOS, E. M.; MARCONI, M. de A. Fundamentos de metodologia científica. 5. ed. São Paulo: Atlas, 2003.

LAUDON, J. P.; LAUDON, K. C. Sistemas de informações gerenciais: Adiministrando a empresa digital. São Paulo: Prentice HalL, 2004.

LUNKES, R. J.; GASPARETTO, V.; SCHNORRENBERGER, D. Um estudo sobre as funções da controladoria. RCO Revista de Contabilidade e Organizações - FEA-RP/USP, v. 4, n. 10, p. 126-126, set./dez. 2010.

MALHOTRA, N. K. Pesquisa de Marketing: uma orientação aplicada. 4. ed. Porto Alegre: Bookman, 2006.

MATIAS-PEREIRA, J. Manual de metodologia da pesquisa científica. 3. ed. São Paulo: Atlas, 2012. 
MINAYO, M. C. (Org.). Pesquisa social: teoria, método e criatividade. Petrópolis: Vozes, 2001.

MOSCOVE, S. A.; SIMKIN, M. G.; BAGRANOFF, N. A. Sistema de informações contábeis. São Paulo: Atlas, 2002.

MOSIMANN, C. P.; FISCH, S. Controladoria: seu papel na administração de empresas. 2. ed. São Paulo: Atlas, 1999.

MOURA, V. de M.; BEUREN, I. M. O papel da Controladoria como suporte ao processo de gestão empresarial. RBC: Revista Brasileira de Contabilidade, v. 29, n. 126, p. 59-67, nov./dez. 2000.

OLIVEIRA, A. G. Uma contribuição ao estudo da contabilidade como sistema de informação ao processo de gestão das micro e pequenas empresas: uma pesquisa no Estado do Paraná. 2004. 232f. Tese (Doutorado) Programa de Pós-Graduação em Engenharia da Produção, Universidade de Santa Catarina, Florianópolis, 2004.

OLIVEIRA, L. M. de; PEREZ JR., J. H.; SILVA, C. A. dos S. Controladoria estratégica. 2. ed. São Paulo: Atlas, 2004.

OLIVEIRA, L. M. de; PEREZ JR., J. H.; SILVA, C. A. dos S. Controladoria Estratégica. 4. ed. São Paulo: Atlas, 2008.

PADOVEZE, C. L. Controladoria estratégica e operacional: conceitos, estrutura, aplicação. 2. ed. rev. e atual. São Paulo: Cengage Learning, 2009.

PADOVEZE, C. L. Contabilidade gerencial: um enfoque em sistema de informação contábil. 7. ed. São Paulo: Atlas, 2010.

PIONTKEWICZ , R. Incorporação da gestão do capital intelectual em um sistema de informação contábil gerencial: um estudo em uma indústria de bens de consumo. 2014. 123f. Dissertação de Mestrado - Universidade Federal do Paraná, Programa Interdisciplinar de Pós-Graduação em Engenharia de Produção, Curitiba, 2014.

PONCIO, N. Apuração de custos na administração pública: a aplicabilidade do Sistema de Informações de Custos do Governo Federal na Polícia Federal. 2013. 111f. Dissertação (Mestrado) - Escola Brasileira de Administração Pública e de Empresas, Centro de Formação Acadêmica e Pesquisa, Fundação Getúlio Vargas, Rio de Janeiro, 2013.

RAUPP, F. M.; BEUREN, I. M. Metodologia da pesquisa aplicável às ciências sociais. In: BEUREN, I. M. (Org.). Como elaborar trabalhos monográficos em contabilidade: teoria e prática. São Paulo: Atlas, 2004. p. 76-97.

SILVA, W. A. C.; CRUZ, A. M.; SOUZA E SILVA, M. O processo de implantação de um Sistema de Informação Contábil: Um estudo de caso em um escritório de contabilidade. 2011. Trabalho de Conclusão de Curso (Graduação em Ciências Contábeis) - Faculdade Novos Horizontes, Belo Horizonte, 2011.

TEIXEIRA, L. P.; GOMES, M. F. M.; SILVA, A. B. O. Construção Civil Mineira: dinâmica e importância para a economia estadual. Revista Brasileira de Gestão e Desenvolvimento Regional, v. 7, p. 69-95, 2011.

TRIVIÑOS, A. N. S. Introdução à pesquisa em ciências sociais: a pesquisa qualitativa em educação: o positivismo, a fenomenologia, o marxismo. São Paulo: Atlas, 1987. 